\title{
Architectuur van het corpus spongiosum: een anatomische studie
}

\author{
Sarah R. Ottenhof ${ }^{1} \cdot$ Petra de Graaf $^{1} \cdot$ Timo F. W. Soeterik $^{1} \cdot$ Lidewij M. F. H. Neeter $^{1} \cdot$ Marijn Zilverschoon $^{2}$ • \\ Matty Spinder $^{2}$ J. L. H. Ruud Bosch ${ }^{1}$ Ronald L. A. W. Bleys ${ }^{2} \cdot$ Laetitia M. O. de Kort $^{1}$
}

Published online: 25 November 2016

(C) The Author(s) 2016. This article is available at SpringerLink with Open Access.

\section{Samenvatting}

Introductie Gedetailleerde kennis van de architectuur van het corpus spongiosum is nodig voor tissue engineering, maar ontbreekt.

Methoden Twee penissen van overleden mannen die hun lichaam ter beschikking van de wetenschap hadden gesteld werden ingevroren; één penis in slappe toestand, de ander artificieel in erectie gebracht. Transversale en frontale (lengterichting) weefselcoupes werden genomen en gekleurd. Na digitalisering werden oppervlakten, vorm en weefseldichtheid gemeten en vergeleken. Ook werden een digitale en een stereolithografische 3D-reconstructie gemaakt.

Resultaten Oppervlaktepercentages van vasculaire holten in beide richtingen lieten een oppervlaktetoename zien in erectie van $127 \%$ transversaal en $140 \%$ frontaal. De transversale coupes hadden een vergelijkbare structuur op de verschillende locaties, maar een grotere weefseldichtheid in de glans penis. De vasculaire holten waren groter in de frontale coupes met meer incomplete septae. Dit werd bevestigd in de 3D-modellen.

Conclusie Deze studie geeft informatie over de architectuur van het corpus spongiosum, die belangrijk is bij tissue engineering.

Dit artikel werd eerder gepubliceerd onder de titel Architecture of the Corpus Spongiosum: An Anatomical Study. J Urol. 2016 Mar;196(3);919-25.

dr. Petra de Graaf

p.degraaf-4@umcutrecht.nl

1 afdeling Urologie, Universitair Medisch Centrum Utrecht, Utrecht, Nederland

2 afdeling Anatomie, Universitair Medisch Centrum Utrecht, Utrecht, Nederland
Trefwoorden penis $\cdot$ corpus spongiosum $\cdot$ urethra $\cdot$ tissue engineering $\cdot$ anatomie

\section{The architecture of the corpus spongiosum: an anatomical study}

\begin{abstract}
Introduction Detailed knowledge on the architecture of the corpus spongiosum is necessary for tissue engineering, but lacking.

Methods Two penises of male cadavers, who donated their bodies for research purposes, were dissected and frozen; one in flaccid state, the other artificially erected. Tissue sections in transverse and frontal (longitudinal) direction were obtained, stained and digitalized. Surfaces, shape and tissue density were measured and compared. Also, a digital and a stereolithografic 3D-reconstruction were made.

Results Area percentages of vascular sinuses in both directions indicated an increase with erection of $127 \%$ transversally and $140 \%$ frontally. The structure of the transverse sections was similar at all section sites, but the glans penis had a higher tissue density. Vascular spaces were larger in frontal sections, with more incomplete septae. 3D-models confirmed these findings.

Conclusion This study provides novel information on the architecture of the corpus spongiosum that is important in tissue engineering.
\end{abstract}

Keywords penis $\cdot$ porpus spongiosum $\cdot$ urethra $\cdot$ tissue engineering · anatomy 


\section{Introductie}

Reconstructieve urethrachirurgie wordt gedaan ter behandeling van urethrastricturen, maar ook om congenitale aandoeningen zoals hypospadie te corrigeren. Bij een urethrastrictuur is het lumen vernauwd als gevolg van een fibrotisch proces. Fibrose kan geïnduceerd worden door een extern trauma, een iatrogeen trauma middels instrumentarium of open chirurgie, infectie of lichen sclerosus [1]. Hypospadie is een congenitale afwijking waarbij de meatus van de urethra niet bij de top van de glans uitkomt, maar meer proximaal, en het corpus spongiosum (CS) (deels) afwezig is $[2,3]$.

Er zijn grofweg twee vormen van urethraplastieken: excisie van het fibrotisch segment met primaire anastomose (EPA), en substitutie-urethraplastiek waarbij niet-urethraal weefsel wordt gebruikt [4]. De EPA-procedure geeft uitstekende resultaten [4-6], maar is alleen toepasbaar op korte anterieure urethrastricturen. Langere of peniele stricturen worden bij voorkeur met een substitutie-urethraplastiek behandeld [1].

Voor hypospadiecorrecties wordt penishuid (ook preputium) gebruikt [3, 7]. Bij een ernstige hypospadie of bij complicaties kan ook in twee tempi geopereerd worden, waarbij wangslijmvlies dikwijls als substituut dient [8]. Naast wangslijmvlies worden ook andere weefsels als vervanging gebruikt, zoals (gevasculariseerde) huid, blaas-, tong- en dunne-darmslijmvlies [9-13].

Helaas hebben deze substituten ook nadelen, zoals recidief van de strictuur, urethrocutane fistel en functieverlies van de donorplaats. De meeste complicaties zijn gerelateerd aan suboptimale doorbloeding door gebrek aan een adequate vaatvoorziening.

Patiënten die met behulp van penishuid behandeld zijn voor een ernstige hypospadie, krijgen veelal zulke problemen nadat zij enige tijd seksueel actief zijn. Dit ondersteunt de hypothese dat coïtus de getransplanteerde penishuid beschadigt indien deze niet gevasculariseerd en ondersteund wordt door een CS.

Wij veronderstellen dat voor de urethra gebruikt substitutieweefsel een functioneel CS nodig heeft om twee redenen: optimalisatie van vaatvoorziening en mechanische ondersteuning tijdens seksuele activiteit. Regeneratie van urethraal weefsel in combinatie met een reconstructie van het omliggend CS, zou kunnen leiden tot verbeterde uitkomsten van reconstructieve urethrachirurgie [14].

Voor het ontwerpen van een scaffold voor de regeneratie van corporaal weefsel is gedetailleerde kennis nodig van de architectuur van het CS. Voor zover ons bekend is, is dit de eerste methodologische en anatomische studie die de interne structuren van het CS beschrijft.

Het doel van deze studie was de kennis over het CS te vergroten door een methode te ontwikkelen die het mogelijk maakt het CS en zijn vasculaire holten te visualiseren en te meten.

\section{Methoden}

\section{Materiaal}

Voor deze studie zijn de penissen van twee ongefixeerde mannelijke lichamen gebruikt. De lichamen kwamen via een donatieprogramma op de afdeling Anatomie van het Universitair Medisch Centrum Utrecht. Beide mannen hadden tijdens hun leven informed consent getekend voor het gebruik van hun lichaam voor onderwijs- en wetenschapsdoeleinden. Bij beide lichamen waren geen tekenen van genitale anomalieën aanwezig.

De lichamen werden voor dissectie in de steensnedeligging gepositioneerd. Via een mediane scrotale en perineale incisie en een dwarse incisie ventraal van de anus werden de complete penissen zorgvuldig uitgenomen. Beide CS bleven intact van de glans tot en met de bulbus penis, evenals de corpora cavernosa.

Vervolgens werd een van beide penissen kunstmatig in erectie gebracht, zoals ook tijdens operaties gebeurt. In het kort: om lekkage te voorkomen, werd er een tourniquet om de basis van de penis gezet (ter hoogte van het ligamentum suspensorium en ligamentum fundiforme). Vervolgens werd er een fysiologische zoutoplossing op verschillende plaatsen in de corpora cavernosa geïnjecteerd totdat een goede erectie bereikt was. Zowel de erecte als de slappe penis werden, liggend op hun dorsale zijde, bevroren tot $-25{ }^{\circ} \mathrm{C}$. Vervolgens werden zij in een zuilvormige mal met een $1 \%$ carboxymethylcellulose (CMC) oplossing geplaatst.

\section{Histologische coupes}

Met een cryomacrotoom (CM3600 XP, Leica Biosystems, Nussloch, Duitsland) werden van beide penissen in twee richtingen histologische coupes gesneden. Eerst werden dwarsdoorsneden genomen (dus het transversale vlak) op zes verschillende plekken: T1 t/m T6 (fig. 1). De afstand tussen deze snijvlakken was bij beide penissen ongeveer $2 \mathrm{~cm}$. Daarna werden elke millimeter lengtedoorsneden genomen (in het frontale vlak): F1 t/m F7 (fig. 1). Met het weefsel op tape geplakt en een messnelheid van $80 \mathrm{~mm} / \mathrm{s}$ werden coupes van $25 \mu \mathrm{m}$ dikte gesneden. Coupes werden direct gefixeerd en ontwaterd in alcohol (achtereenvolgens $70 \%$ en $96 \%$ alcohol).

$\mathrm{Na} 30$ seconden incubatie in water werden de coupes $10 \mathrm{sec}$ gekleurd in een aangepaste Mallory-Cason-oplossing $(0,5 \%$ fosforwolfraamzuur, $1 \%$ orange $\mathrm{G}, 0,5 \%$ aniline blauw en $1,5 \%$ fuchsinezuur), gespoeld in water $(30 \mathrm{sec})$ 


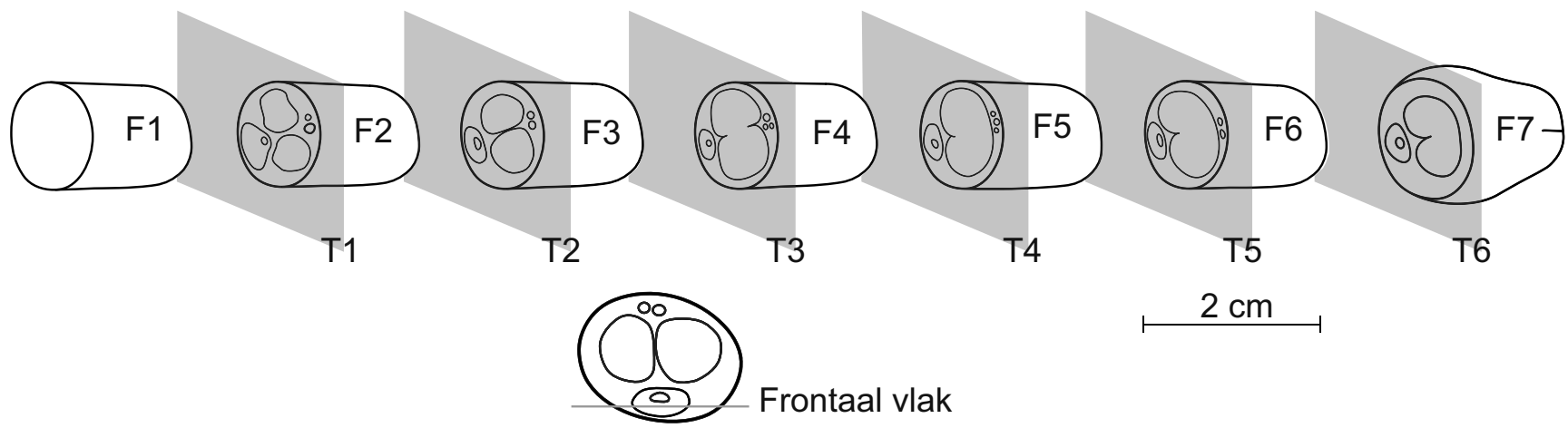

Figuur 1 Schematisch overzicht van de snijlocaties.

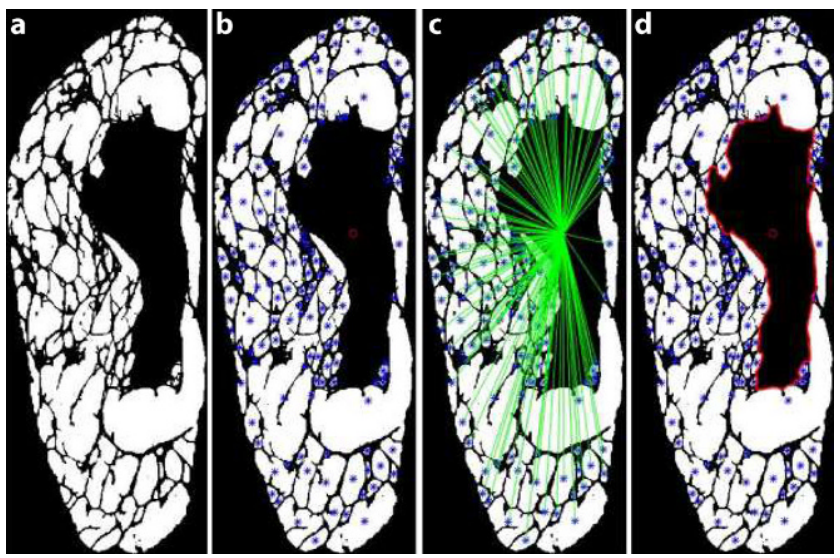

Figuur 2 Matlabanalyse van sectie T5-1. a Zwart-wit figuur. b Zwaartepunten van de holten (blauwe sterren) en de urethra (rode stip) die zijn weergegeven op het zwart-witfiguur zoals in a. c De groene lijnen geven de afstand weer tussen de zwaartepunten van de holten en het zwaartepunt van de urethra. d Alle zwaartepunten van de holten en de omtrek van de urethra (rode lijn) getekend op a.
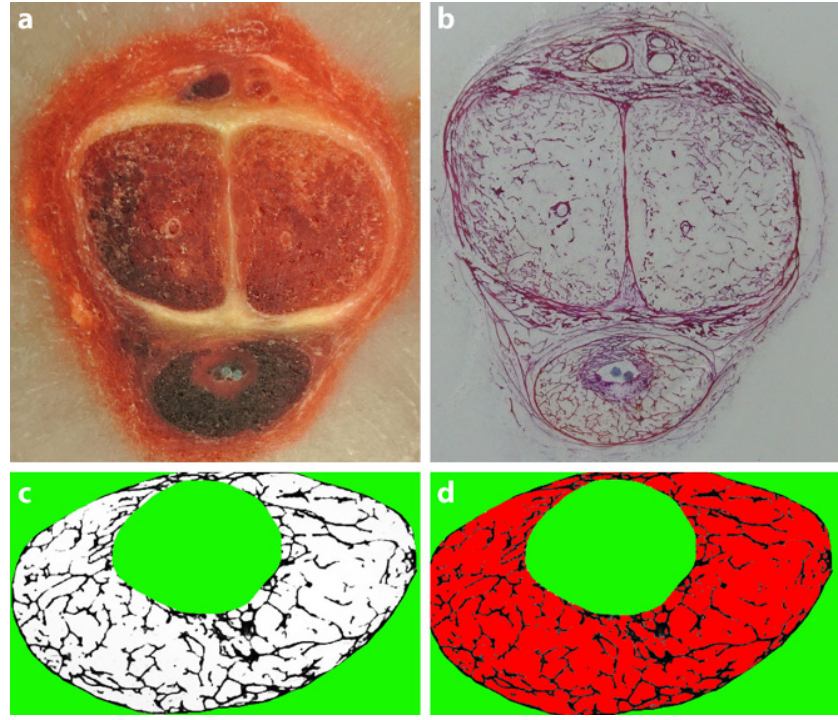

Figuur 3 Overzicht van de oppervlaktebepalingen. a Snijvlak van de ongefixeerde, bevroren erecte penis op T3. b Gekleurde coupe geplakt op filterpapier. c Binaire afbeelding van het CS, urethra verwijderd (Photoshop). d CS afbeelding met vasculaire holten geselecteerd voor oppervlakte bepalingen (Image J).

lecteerd en gemeten in pixels en vervolgens genoteerd als percentage van het totale CS oppervlak.

Het tellen van het aantal holten en het meten van zowel de oppervlakten per holte in pixels als de afstand van de holte tot de urethra werd gedaan met Matlab-software (versie R2015a, The MathWorks, Inc). Afbeeldingen in grijswaarden werden geïmporteerd uit Adobe Photoshop en geconverteerd naar zwart-witafbeeldingen, waarbij de holten wit waren en het lumen van de urethra zwart (fig. 2a). Een voorwaarde voor de Matlab-analyse was dat het urethralumen geheel omringd werd door CS. De holten werden op twee manieren gesorteerd: op maat en op basis van de afstand van de holte tot de urethra (zwaartepunt tot zwaartepunt of zwaartepunt tot omtrek). Een nadeel van het bepalen van de zwaartepunt tot zwaartepunt (c2c) afstand is de sensitiviteit voor de vorm van het urethrale lumen. De afstand van een holtezwaartepunt en het dichtstbijzijnde punt in de 
Tabel 1 Oppervlakte van de vasculaire holten (\%) in het transversale vlak van de slappe en de erecte penis.

\begin{tabular}{llllllll}
\hline- & Loc. T1 & Loc. T2 & Loc. T3 & Loc. T4 & Loc.T5 & Loc. T6 & gemiddelde \\
\hline erecte penis & $56,7 \%$ & $60,8 \%$ & $57,0 \%$ & $59,3 \%$ & $63,9 \%$ & $59,1 \%$ & $59,5 \%$ \\
& $\pm 1,5$ & $\pm 3,9$ & $\pm 1,0$ & $\pm 2,4$ & $\pm 3,5$ & $\pm 1,6$ & $\pm 2,7$ \\
& $(n=3)$ & $(n=4)$ & $(n=3)$ & $(n=5)$ & $(n=3)$ & $(n=5)$ & $76,8 \%$ \\
slappe & $78,9 \%$ & $70,2 \%$ & $78,7 \%$ & $80,2 \%$ & $74,6 \%$ & $76,6 \%$ & $\pm 3,7$ \\
penis & $\pm 0,6$ & $\pm 3,5$ & $\pm 2,4$ & $\pm 4,1$ & $\pm 2,1$ & $(n=7)$ & $(n=5)$ \\
& $(n=3)$ & $(n=3)$ & $(n=3)$ & $(n=5)$ & $(n=3)$ & & \\
\hline
\end{tabular}

urethraomtrek (c2u_o) is minder sensitief voor de vorm van het lumen. Oppervlakten en afstanden werden in elke coupe in eerste instantie in pixels gemeten, en daarna op basis van kalibrerende metingen op niet-digitale coupes, omgezet naar millimeter $(\mathrm{mm})$ of vierkante $\mathrm{mm}\left(\mathrm{mm}^{2}\right)$. Holten met een oppervlakte kleiner dan $0,01 \mathrm{~mm}^{2}$ werden beschouwd als artefacten en eruit gefilterd. Holten werden in vijf oppervlaktegroepen verdeeld: $0,01-0,05 \mathrm{~mm}^{2} ;>0,05-0,1 \mathrm{~mm}^{2}$; $>0,1-1 \mathrm{~mm}^{2} ;>1-5 \mathrm{~mm}^{2}$ en $>5 \mathrm{~mm}^{2}$. Ook werden ze in vijf afstandsgroepen verdeeld: $0-1 \mathrm{~mm} ;>1-2 \mathrm{~mm} ;>2-4 \mathrm{~mm}$; $>4-6 \mathrm{~mm} ;>6 \mathrm{~mm}$. Het Matlab-script gaf een tabel waarin

a
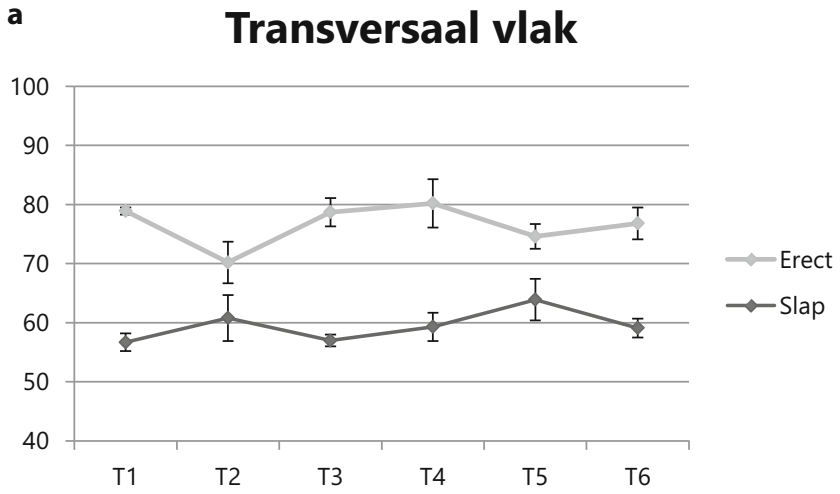

b $\quad$ Frontaal vlak

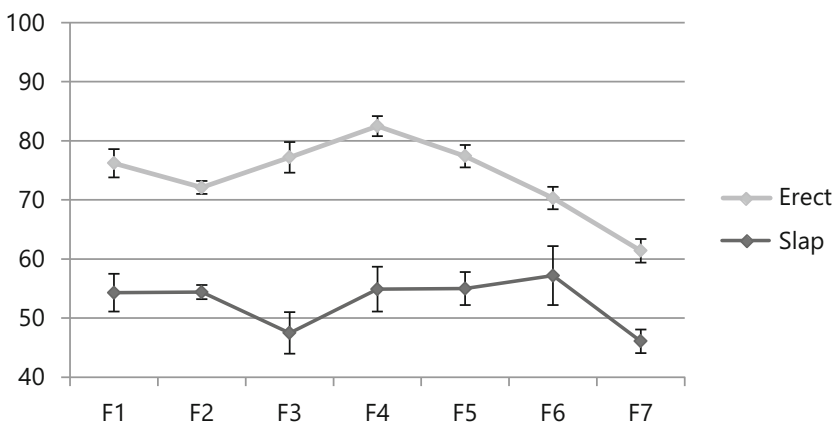

Figuur 4 Vasculair oppervlak (\%) in het transversale en frontale vlak. Het oppervlakte van de vasculaire holten werden berekend zoals beschreven in de Methoden. Minstens 3 coupes werden gebruikt per snijvlak. In het transversale vlak: gemiddelde oppervlakte van de vasculaire holten is weergegeven in tab. 1 en in paneel a. In het longitudinale vlak: gemiddelde oppervlakte van de vasculaire holten is weergegeven in tab. 2 en in paneel $\mathbf{b}$. holten op oppervlakte en afstand worden ingedeeld. Dit script is op verzoek beschikbaar.

\section{D-reconstructie}

Van geïmporteerde tiff/jpg-afbeeldingen van opeenvolgende coupes werden met behulp van VP Microlab (Virtual proteins International, Eindhoven, Nederland) driedimensionale (3D) reconstructies van verschillende segmenten van de erecte penis gemaakt. Overbodige pixels (achtergrond) werden verwijderd met behulp van Adobe Photoshop CS6. Er werd een alphakanaal (http://www.axialis.com/tutorials/ tutorial-misc001.html) gebruikt, zodat alleen CS-pixels getoond werden in het 3D-model. Na het instellen van een afstand tussen de coupes in VP Microlab, konden delen van het CS driedimensionaal gereconstrueerd worden. De digitale 3D-reconstructie kon vrij geroteerd en vergroot worden.

\section{Resultaten}

\section{Materiaal}

Er waren twee mannelijke lichamen (59 en 91 jaar oud) beschikbaar; beiden zonder zichtbare anatomische of urogenitale anomalieën. De totale lengte in slappe toestand van de eerste (en later erecte) penis was $25 \mathrm{~cm}$, de tweede penis was $22 \mathrm{~cm}$.

\section{Histologische coupes}

Cryosectie en histologie leverden duidelijk gekleurde coupes op, met een groot contrast tussen de vasculaire holte en septae. Het weefselnetwerk van het CS kon tot in detail gevisualiseerd worden (fig. 3). In totaal werden 97 coupes gebruikt voor de oppervlaktemetingen.

\section{Oppervlak van vasculaire holten}

In het transversale vlak varieerde het gemiddelde relatieve oppervlak van de vasculaire holten per afnameplaats van 56,7 tot $63,9 \%$ in de slappe penis, en van 70,2 tot $80,2 \%$ in de erecte penis (tab. 1). In het frontale vlak was dit respectievelijk 46,1 tot $57,2 \%$ en 61,4 tot $82,5 \%$ (tab. 2). 
Tabel 2 Oppervlakte van de vasculaire holten (\%) in het longitudinale vlak van de slappe en de erecte penis.

\begin{tabular}{lllllllll}
\hline- & Loc. F1 & Loc. F2 & Loc. F3 & Loc. F4 & Loc. F5 & Loc. F6 & Loc. F7 & gemiddelde \\
\hline erecte & $54,3 \%$ & $54,4 \%$ & $47,5 \%$ & $54,9 \%$ & $55,0 \%$ & $57,2 \%$ & $46,1 \%$ & $52,8 \%$ \\
penis & $\pm 3,2$ & $\pm 1,2$ & $\pm 3,5$ & $\pm 3,8$ & $\pm 2,8$ & $\pm 5,0$ & $\pm 2,0$ & $\pm 4,2$ \\
& $(n=4)$ & $(n=3)$ & $(n=5)$ & $(n=4)$ & $(n=4)$ & $(n=4)$ & $(n=4)$ & $71,4 \%$ \\
slappe & $76,2 \%$ & $72,1 \%$ & $77,2 \%$ & $82,5 \%$ & $77,4 \%$ & $70,3 \%$ & $73,9 \%$ & $\pm 2,0$ \\
penis & $\pm 2,4$ & $\pm 1,1$ & $\pm 2,6$ & $\pm 1,7$ & $\pm 1,9$ & $\pm 1,9$ & $\pm 2,8$ \\
& $(n=3)$ & $(n=3)$ & $(n=3)$ & $(n=4)$ & $(n=4)$ & $(n=4)$ & $(n=3)$ & \\
\hline
\end{tabular}

Fig.4a laat zien dat in het transversale vlak de metingen per penis niet substantieel verschilden, maar dat in het frontale vlak het vasculaire oppervlak afnam in de distale richting (fig. 4b). In de glans penis (snijvlak F7) was er relatief minder vasculair oppervlak dan op andere snijvlakken, met relatief meer bindweefsel (fig. 5).

In het transversale vlak werd een gemiddeld vasculair oppervlak gemeten van 59,5\% (SD 2,7\%) in de slappe penis en 76,6\% (SD 3,7\%) in de erecte penis. In het frontale vlak was dat 52,8 \% (SD 4,2\%) en 73,9 (SD 6,8\%) (tab. 1 en 2). Dit komt overeen met een relatieve toename van $129 \%$ in het transversale vlak, en $140 \%$ in het frontale vlak. Het grootste transversale verschil ('toename') was ter plaatse van $\mathrm{T} 1$ en $\mathrm{T} 4$, het grootste frontale verschil was in het midden (snijvlak F4).

\section{Vorm van de vasculaire holten}

In fig. 6 is het patroon van de transversale coupes van T4 weergegeven. De vasculaire holten varieerden van elliptisch tot rond van vorm. De meesten werden gescheiden door incomplete septae, waardoor een groot continu netwerk gevormd werd. In de frontale richting waren de holten anders gevormd dan in de transversale richting, met meer incomplete septae en meer verbindingen in alle mogelijke richtingen tussen relatief grote vasculaire holten. Hierdoor waren oppervlaktemetingen per vasculaire holte niet uitvoerbaar.

\section{Patroon van de vasculaire holten}

De vorm van het urethrale lumen veranderde in de negen coupes van T1-T6 van ovaal tot hoefijzervormig, waardoor het c2u_o-script beter toepasbaar was dan het c2c-script. Met het c2u_o-script werden er van T1 t/m T6 tussen de 89 en 174 holten per coupe geteld (gemiddeld 125,9; SD $=28$ ) [15]. Een duidelijk patroon in de verdeling van de holten per coupe werd niet gezien. Wel was er een grote variatie in holteoppervlak, zelfs drie nabijgelegen coupes ( $50 \mu \mathrm{m}$ uit elkaar) verschilden sterk van elkaar [15].

\section{D-reconstructie met de weefselcoupes}

De 3D-reconstructie van de erecte penis zoals te zien in het online videobestand bevestigde de aanwezigheid van verbindingen tussen de vasculaire holten in alle mogelijke richtingen [16]. Ook bevestigde deze reconstructie dat septae vanuit verschillende hoeken in de holten steken. Een minderheid van de holten werd gescheiden door complete septae, veelal in transversale richting. In longitudinale richting strekten de holten zich uit en waren zij verbonden met elkaar.

\section{Discussie}

Wij presenteren een nieuwe methode om de weefsels van het corpus spongiosum te snijden en kleuren, in combinatie met een methode voor relatieve oppervlaktemetingen, berekeningen van expansie en patroonanalyse. De toegepaste methode voorkomt artefacten door krimp, zwelling of manipulatie. De resultaten van deze studie geven ons nieuwe informatie over de interne architectuur van het CS in de slappe en erecte penis. Voor zover ons bekend, is dit de eerste studie die de architectuur van het CS beschrijft op basis van metingen op ware grootte. Er zijn studies die zich richten op de ultrastructuur van de urethra, maar deze nemen het omliggende CS niet mee in hun beschrijvingen [17-20].

In het transversale vlak besloegen vasculaire holten $60 \%$ in de slappe penis en $77 \%$ in de erecte. In het frontale vlak was dit respectievelijk $53 \%$ en $74 \%$. In de glans werd een dichter weefselnetwerk gemeten dan in de rest van het CS. Dit komt overeen met de bevindingen van Hsu et al., die vonden dat de glans voornamelijk uit collageen bestaat met daarnaast een hoge concentratie elastinevezels. Dit elastine in de glans kan drukkrachten tijdens seksuele activiteit absorberen [21].

Kleuring met de aangepaste Mallory-Cason-oplossing gaf een duidelijke weergave van de vezelachtige trabekels in het CS. Om verschillende typen collageen en elastine te onderscheiden, zouden meer kwalitatieve kleuringen gedaan moeten worden, hetzij met Sirius-Red en gepolariseerd licht, hetzij immunohistochemisch met antilichamen 
Hier staat een advertentie.

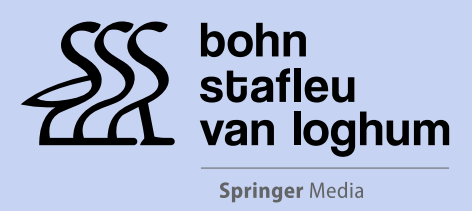

Houten 2017 
Hier staat een advertentie.

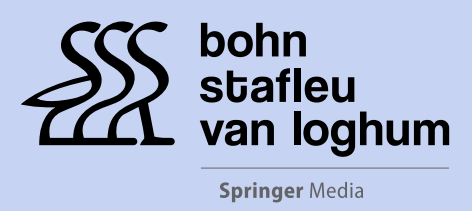

Houten 2017 


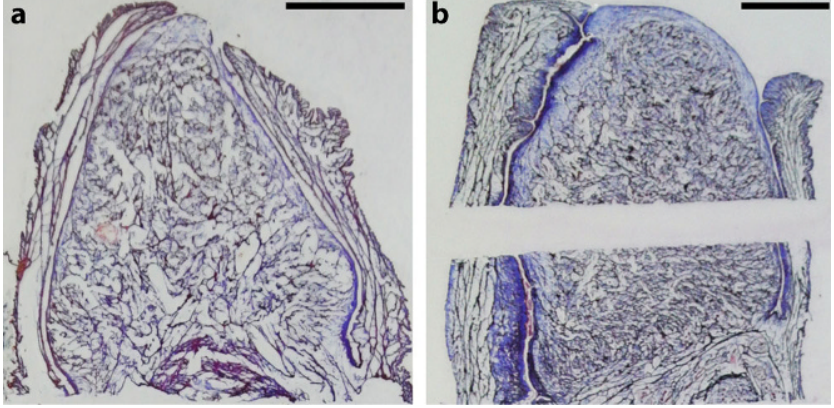

Figuur 5 Voorbeeld van met Mallory-Cason gekleurde coupes van de glans penis. a Frontale coupe van de slappe penis (F7). b Frontale coupe van de erecte penis (F7). Schaalbalk komt overeen met $10 \mathrm{~mm}$.
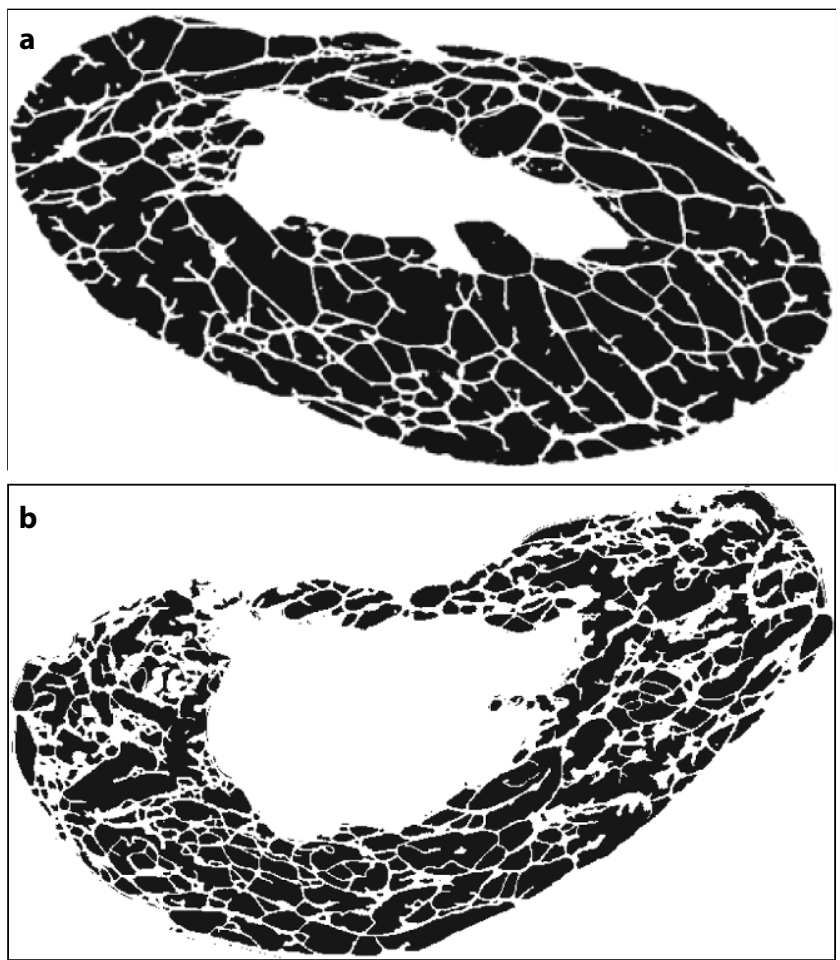

Figuur 6 Binaire afbeeldingen van de transversale coupes. Representatieve afbeeldingen van transversale coupes van beide penissen werden verwerkt zoals beschreven in de Methodensectie en in fig. 3 . Transversale coupes (T4) van de erecte penis (a) en van de slappe penis (T4) (b). Afbeeldingen van het CS werden binair gemaakt (zoals beschreven in de Methodensectie) voor oppervlaktebepalingen. In beide figuren: het zwarte oppervlakte representeert het oppervlak van de vasculaire holte, het wit representeert de septae.

tegen de verschillende componenten van de trabekels (de extracellulaire matrix).

Het verschil in vasculaire holte tussen de slappe en de erecte penis was $129 \%$ in het transversale vlak en $140 \%$ in het frontale vlak. Dit kan worden gezien als een surrogaat voor expansie, maar moet voorzichtig geïnterpreteerd worden, omdat de metingen in twee verschillende penissen gedaan zijn. In levende mannen is de veronderstelde toename van de penis in erectie (gemiddeld) $125 \%$ in omtrek en $143 \%$ in de lengte, overeenkomstig met onze bevindingen [22].

We observeerden een verschil in het aantal holten tussen de slappe en erecte penis, namelijk minder holten in de erecte toestand. Dit zou een gevolg kunnen zijn van veranderende verbindingen tussen weefselschotten: in slappe toestand staan zij in verbinding met het tegenoverstaande weefselschot, in erecte toestand niet. Door deze 'zwevende schotten' is de afscheiding tussen twee holten niet meer compleet en worden zij één. Deze bevindingen kunnen ook resulteren uit inter-individuele variatie, we hebben immers slechts twee penissen onderzocht.

In tegenstelling tot het CS, is er meer bekend over de architectuur van de corpora cavernosa [21, 23, 24]. Goldstein et al. hebben het intracaverneuze spierweefsel en het caverneus fibrotisch skelet vergeleken tussen penissen in erectie en in slappe toestand. Zij vonden prominente vasculaire holten die gescheiden werden door incomplete fibromusculaire bundels. De slappe penis leek te bestaan uit bundels glad spierweefsel en een (verondersteld) netwerk van samengevallen intercommunicerende vasculaire holten [23, 24]. Alhoewel het niet duidelijk is of het humane CS ook voornamelijk uit bundels glad spierweefsel bestaat, komt deze beschrijving van het fysiologische gedrag van de corpora cavernosa overeen met de structurele patronen van het CS in de huidige studie. Phillips et al. hebben met MRI de peniele corpora in beeld gebracht, maar de resolutie is te laag om vasculaire septae te onderscheiden [25].

Het doel van deze studie was een methode te ontwikkelen waarmee de architectuur van de vasculaire holten en het bindweefsel van het CS op ware grootte afgebeeld en gemeten kan worden. De data werden verzameld als relatieve oppervlakten van vasculair holten in zowel de slappe als de erecte penis. Deze data geven een idee van de benodigde architectuur en dichtheid die een scaffold moet hebben voor tissue engineering van een CS. Tot nu toe worden gedecellulariseerde matrices gebruikt om tissue engineering van corpora te onderzoeken [26]. Ontwikkelingen in materiaalkennis hebben geleid tot biogeactiveerd scaffoldmateriaal dat endogene celgroei stimuleert [27]. Bij het ontwerpen van een biogeactiveerde scaffold moet rekening gehouden worden met de structurele veranderingen die gepaard gaan met erectie en detumescentie. Verder onderzoek moet de fysische karakteristieken zoals rekbaarheid en histologische kenmerken van het CS bepalen. Een kwantitatieve analyse van erectiel weefsel door Gallo et al. liet zien dat er meer collageen dan gladde spier of elastinevezels in het CS was, en zelfs meer collageen in het CS dan in de CC [28]. Aangezien die studie in foetussen is gedaan, moeten de resultaten voorzichtig geïnterpreteerd worden.

Het gebruik van dit protocol maakt het mogelijk om anatomische structuren te visualiseren en analyseren, inclusief het netwerk van complete en incomplete septae, zoals in 
de levende patiënt. De 3D-reconstructie van delen van het CS van de erecte penis geeft unieke extra inzichten in de interne structuur van het CS.

De huidige studie heeft een aantal beperkingen. Omdat lichamen beperkt beschikbaar waren en bovendien kostbaar, zijn er slechts twee lichamen onderzocht. Dit maakte het onmogelijk om normale variatie te bepalen. Om die reden kunnen de geobserveerde verschillen tussen slap en erect ook toegeschreven worden aan interindividuele variatie. Ook de leeftijden en navenante hormoonstatussen van de lichamen kunnen de uitkomsten hebben beïnvloed. Het is bekend dat androgenen de ontwikkeling, groei en status van peniel erectiel weefsel beïnvloedt [29]. De leeftijden van deze lichamen waren weliswaar bekend, de hormoonstatussen waren dat niet. Een vergelijking van meer penissen, bij voorkeur in verschillende leeftijdsgroepen, zal meer onthullen over de natuurlijke variatie van de architectuur, de ratio weefsel/vaatholte en het patroon van vasculaire holten. Ondanks de beperkingen kunnen de in deze studie beschreven technieken gebruikt worden als protocol in toekomstig onderzoek en in grotere studies.

\section{Conclusie}

Deze studie beschrijft een protocol voor het snijden en kleuren van peniel spongieus weefsel, gevolgd door digitale analyse en 3D-reconstructie. Onze resultaten geven nieuwe informatie over de architectuur en weefselkarakteristieken van het CS, die essentieel zijn voor het ontwerpen van een scaffold voor toekomstige tissue engineering van het CS. Onze resultaten kunnen helpen bij het plannen en ontwerpen van een 3D-print van een scaffold. Uitbreiding van deze studie met meer onderzoeksmateriaal van verschillende leeftijden is aanbevolen.

Dankbetuiging Met dank aan Simon Plomp en Fiona van Zoomeren voor de organisatie en logistiek van de gebruikte stoffelijk overschotten.

Open Access This article is distributed under the terms of the Creative Commons Attribution 4.0 International License (http:// creativecommons.org/licenses/by/4.0/), which permits unrestricted use, distribution, and reproduction in any medium, provided you give appropriate credit to the original author(s) and the source, provide a link to the Creative Commons license, and indicate if changes were made.

\section{Literatuur}

1. Mundy AR, Andrich DE. Urethral strictures. BJU Int. 2011;107: 6-26.

2. Baskin LS. Hypospadias and urethral development. J Urol. 2000;163:951-6.

3. Baskin LS, Ebbers MB. Hypospadias: anatomy, etiology, and technique. J Pediatr Surg. 2006;41:463-72.
4. Barbagli G, De Angelis M, Romano G, Lazzeri M. Long-term followup of bulbar end-to-end anastomosis: a retrospective analysis of 153 patients in a single center experience. J Urol. 2007;178:2470-3.

5. Micheli E, Ranieri A, Peracchia G, Lembo A. End-to-end urethroplasty: long-term results. BJU Int. 2002;90:68-71.

6. Santucci RA, Mario LA, McAninch JW. Anastomotic urethroplasty for bulbar urethral stricture: analysis of 168 patients. J Urol. 2002;167:1715-9.

7. Snodgrass WT. Tubularized incised plate (TIP) hypospadias repair. Urol Clin N Am. 2002;29:285-90.

8. Bracka A. A versatile two-stage hypospadias repair. Br J Plast Surg. 1995;48:345-52.

9. Liu JS, Han J, Said M, et al. Long-term outcomes of urethroplasty with abdominal wall skin grafts. Urology. 2015;85:258-62.

10. Ozgok Y, Ozgur Tan M, Kilciler M, et al. Use of bladder mucosal graft for urethral reconstruction. Int J Urol. 2000;7:355-60.

11. Palminteri E, Berdondini E, Fusco F, et al. Long-term results of small intestinal submucosa graft in bulbar urethral reconstruction. Urology. 2012;79:695-701.

12. Song LJ, Xu YM, Lazzeri M, Barbagli G. Lingual mucosal grafts for anterior urethroplasty: a review. BJU Int. 2009;104:1052-6.

13. Warner JN, Malkawi I, Dhradkeh M, et al. A Multi-institutional evaluation of the management and outcomes of long-segment urethral strictures. Urology. 2015;85:1483-7.

14. Kemp V de, Graaf P de, Fledderus JO, et al. Tissue engineering for human urethral reconstruction: systematic review of recent literature. PLOS ONE. 2015;10:e118653.

15. Ottenhof SR, Graaf P de, Soeterik TF, et al. Architecture of the corpus spongiosum: an anatomical study. J Urol. 2016;196:919-25.

16. Zilverschoon, Zilverschoon M. Videobestand, upload door Marijn Zilverschoon, Penis3, gemaakt op 18 juni 2015 2015. https://www. youtube.com/watch?v=pSBoSJ5oorg. Geraadpleegd op: 25 oktober 2016.

17. Kock ML de, Burger EG. A histological study of the urethra of the male baboon - is it similar to man's? J Urol. 1985;134:617-9.

18. Hakky SI. Ultrastructure of the normal human urethra. Br J Urol. 1979;51:304-7.

19. Zecchi-Orlandini S, Gulisano M, et al. Scanning electron microscopic observations on the epithelium of the human spongy urethra. Andrologia. 1988;20:132-7.

20. Zecchi-Orlandini S, Orlandini GE. Ultrastructure of human male urethra. Arch Androl. 1989;23:51-9.

21. Hsu GL, Brock G, Heyden B von, et al. The distribution of elastic fibrous elements within the human penis. $\mathrm{Br} \mathrm{J}$ Urol. 1994;73:566-71.

22. Veale D, Miles S, Bramley S, et al. Am I normal? A systematic review and construction of nomograms for flaccid and erect penis length and circumference in up to 15521 men. BJU Int. 2015;115:978-86.

23. Goldstein AM, Meehan JP, Morrow JW, et al. The fibrous skeleton of the corpora cavernosa and its probable function in the mechanism of erection. Br J Urol. 1985;57:574-8.

24. Goldstein AM, Padma-Nathan H. The microarchitecture of the intracavernosal smooth muscle and the cavernosal fibrous skeleton. J Urol. 1990;144:1144-6.

25. Phillips TR, Wright DK, Gradie PE, et al. A comprehensive atlas of the adult mouse penis. Sex Dev. 2015;9:162-72.

26. Eberli D, Susaeta R, Yoo JJ, Atala A. A method to improve cellular content for corporal tissue engineering. Tissue Eng Part A. 2008;14:1581-9.

27. Muylaert DE, Almen GC van, Talacua H, et al. Early in-situ cellularization of a supramolecular vascular graft is modified by synthetic stromal cell-derived factor-1alpha derived peptides. Biomaterials. 2016;76:187-95. 
28. Gallo CB, Costa WS, Furriel A, et al. Modifications of erectile tissue components in the penis during the fetal period. PLOS ONE. 2014;9:e106409.

29. Traish A, Kim N. The physiological role of androgens in penile erection: regulation of corpus cavernosum structure and function. J Sex Med. 2005;2:759-70.

drs. Sarah R. Ottenhof arts

dr. Petra de Graaf celbioloog drs. Timo F.W. Soeterik arts

drs. Lidewij M.F.H. Neeter technische geneeskunde drs. Marijn Zilverschoon promovendus anatomie drs. Matty Spinder anatoom

prof. dr. J.L.H. Ruud Bosch uroloog

prof. dr. Ronald L.A.W. Bleys anatoom

dr. Laetitia M.O. de Kort uroloog 